\title{
Desigualdades regionales en planificaciones desarrollistas. Una revisión del proceso de territorialización de Río Negro 1958-1976 ${ }^{1}$
}

\author{
Paula Núñez y y Silvana López ${ }^{3}$
}

\begin{abstract}
RESUMEN
El estudio indaga en la dinámica de construcción de fronteras y diferencias al interior de la provincia de Río Negro, tomando como punto de inflexión la provincialización en 1958. Se busca evidenciar cómo se continuó con la fragmentación espacial de los años previos, profundizando y modificando las escisiones al restringir lo provincial a los intereses de ciertos sectores regionales.

Para ello abordaremos un conjunto de fuentes escasamente analizadas: la Constitución provincial redactada en 1957 y los planes de desarrollo de los gobiernos entre 1958 y 1976. Avanzaremos en los debates asociados a la construcción jerárquica de las regiones, ejemplificando cómo la transformación espacial habilita, paradójicamente, la asunción del espacio no solo como neutro, sino como marco justificado de una integración social desigual, que para el año 1973 ya comienza a plantearse en términos de determinismo geográfico, pues las desigualdades se justifican en descripciones del paisaje.
\end{abstract}

Palabras clave: Desarrollismo, Planificación, Río Negro, Paisaje, Jerarquía

\begin{abstract}
This manuscript studies the dynamics of constructing boundaries and the differences within the Río Negro province. We consider 1958, the year the province was established, as a point of inflection in the region. The article seeks to show how the spatial fragmentation of previous years continued, deepening and changing provincial divisions through the restrictions of general interests to certain regional sectors.

To this end, we will analyze rarely cited sources: the provincial constitution drafted in 1957 and the government development plans from 1958 and 1976. We will discuss the associated hierarchical construction of regions, illustrating how spatial transformation enabled, paradoxically, the assumption of territory not only as a neutral act, but as justified under an unequal social integration, which by 1973 was beginning to arise in terms of geographical determinism, as inequalities were justified by descriptions of the landscape.
\end{abstract}

Key words: Developmentalism, Planning, Río Negro, Landscape, Hierarchy

\footnotetext{
1 Artículo recibido el 29 de diciembre de 2014, aceptado el 7 de julio de 2015 y corregido el 31 de julio de 2015.
}

\footnotetext{
2 IID y PCA, Universidad Nacional de Río Negro CONICET (argentina). E- mail: pnunez@unrn.edu.ar

3 INTA Bariloche (Argentina).
} 
El presente artículo indaga en las dinámicas de territorialización, esto es, los procesos de identificación, definición y producción de un espacio como territorio (Monnet, 1999), a partir de la organización espacial de la provincia de Río Negro iniciada en 1958 (ver Figura $N^{0} 1$ ). Esta provincia se constituyó desde los ideales del desarrollismo y adopta en su armado perspectivas teóricas de pensadores como Rogelio Frigerio (1963, 1967) o Raúl Prebisch (1988), quienes reflexionan sobre desigualdades estructurales y proponen vías de solución ligadas a nuevos parámetros de industrialización (García Bossio, 2012; Leiva Lavalle, 2012). En Río Negro esta implementación tuvo, como resultado estructural, la profundización de fronteras internas y diferencias en la provincia que nos Ilevan a preguntarnos tanto por los modos de implementación como por las teorías.

El objetivo de la presente reflexión es evidenciar cómo, en el marco de un plan de crecimiento desarrollista, apelando a una retórica de integración y equidad, se van construyendo desigualdades al interior del espacio devenido en territorio provincial. Esto nos lleva a problematizar las políticas de regionalización y los imaginarios geográficos que sostienen esas iniciativas. Analizaremos contradicciones de las teorías institucionalizantes del período (Ganiza, 2013; Bielschowsky, 2010; Hiernaux, 2013), y nos centraremos en una reflexión escasamente recorrida, la de la territorialización en un espacio de "fracasos", pues se trata de un espacio que, por el armado provincial, se reconoce como ajeno al desarrollo que buscó instituirse. Si bien Río Negro hereda la fragmentación espacial de los años previos, las intervenciones estatales que apelan a propuestas ligadas al desarroIlo armónico y equitativo de una industria equilibradora de las desigualdades previas, paradójicamente profundizan y modifican las escisiones.

Para analizar esta distancia entre teoría y práctica abordaremos un conjunto de fuentes escasamente analizadas, los planes de desarrollo estructurantes del espacio y de la política en el período constitutivo de la provincia. Los documentos centrales son a) el PRO -5 Programa de Desarrollo de Río Negro 1960-1964, b) el compendio "3 años de gobierno", que resume el accionar del primer gobierno elegido de 1958 a 1961, c) el texto "Panorama Río Negro" que es la publicación oficial de la visión de la provincia durante el segundo gobierno elegido, el de Carlos Nielsen (1964-1966), y d) el Plan Trienal 19741976 que refiere a los ideales del peronismo ${ }^{4}$ aplicados en Río Negro. Cabe destacar que el período que nos ocupa se caracteriza por la inestabilidad política. Frente a los sucesivos quiebres institucionales reparamos en fuentes de los gobiernos electos, pues en ellos se considera la organización espacial en diálogo con el ejercicio de representación ciudadana. A este análisis se agrega el diálogo con otras fuentes analizadas en estudios precedentes, aunque desde perspectivas distintas, como es la Constitución provincial redactada en 1957, el digesto legal, fuentes periodísticas, libros de historia provincial, además de fuentes secundarias que se irán introduciendo en diálogo con el corpus central.

Cabe mencionar que, por una cuestión de extensión no abordaremos el detalle de los cambios en el conjunto de actividades productivas y actores asociados en cada uno de los recortes políticos. Dado que el objetivo es evidenciar dinámicas de territorialización divergentes focalizaremos, en cada uno de los gobiernos, una actividad que nos resulta representativa de la mirada de esa gestión en el espacio. Así introduciremos la producción futihortícola en la primera gestión, el turismo en la segunda y la producción ovina en la tercera.

A partir del análisis de estos documentos, y a la luz de los focos particulares desde los cuales los interpretamos, buscamos dar cuenta la dimensión temporal y subjetiva del reconocimiento del espacio, en un proceso en el cual los sentidos y las pertenencias se instituyen y resignifican en la dinámica política que se inaugura en 1958. Vale destacar que referimos nuestra perspectiva institucional a las reflexiones de Fernández et al. (2012) quienes

\footnotetext{
4 Movimiento político argentino, organizado en torno a la figura de Juan Domingo Perón entre 1945 y 1955. La referencia no es menor porque la organización que indagamos refiere al gobierno que se inicia tras el derrocamiento de este presidente, terminando en la gestión que lo tiene nuevamente a cargo del Poder Ejecutivo Nacional.
} 
sostienen que "... las instituciones consisten en 'una serie de reglas persistentes y conectadas formales e informales, que prescriben la actuación de la conducta, constriñen la actividad, y dan forma a las expectativas'..." (Keohane, 1993 en: Fernández et al., 2012: 23). Esta reflexión abre la necesidad de distinguir dinamismos, pues la diferencia entre las organizaciones y el ambiente institucional no es sencillo. En nuestro caso, el principal orden de institucionalización va a referirse al armado provincial. De allí la trama de acuerdos se observará a partir de problematizar referencias materiales tomadas de la geografía física como fundamento de la constitución del "plano simbólico" que delineó la institu- cionalización de otras organizaciones presentes en el territorio.

En nuestro estudio, avanzamos en los debates asociados a la construcción jerárquica, pluriescalar, abierta y relacional de las regiones internas de la provincia, ejemplificando cómo el reconocimiento y la transformación espacial habilita, paradójicamente, la asunción del espacio no solo como neutro, sino como marco justificativo de una integración social desigual, que para el año 1973 ya comienza a plantearse en términos de determinismo geográfico, pues las desigualdades se justifican en descripciones del paisaje (Figura $\mathrm{N}^{\mathrm{0}} 1$ ).

Figura $N^{0} 1$

Detalle físico y político de la Provincia de Río Negro

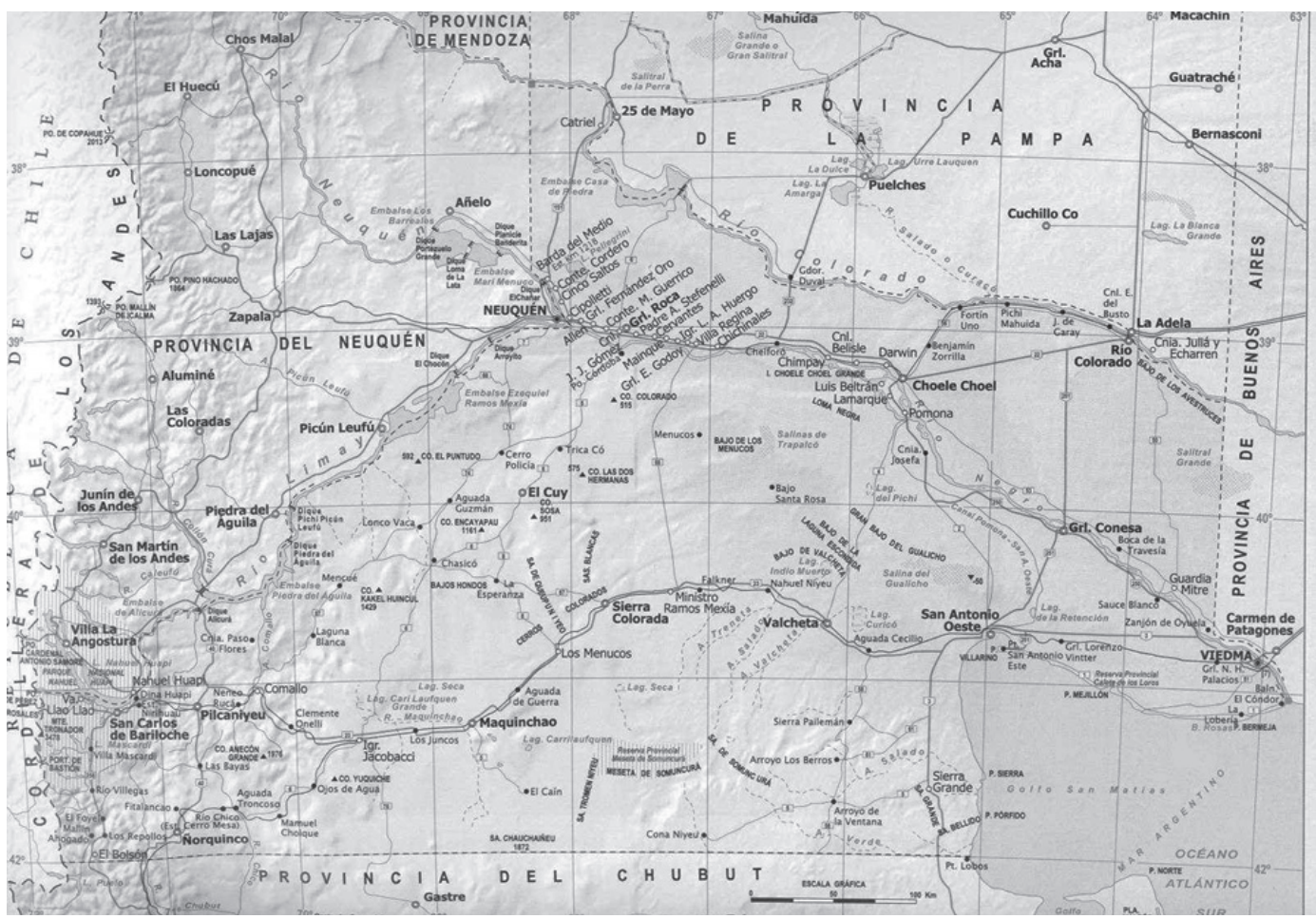

Fuente: Instituto Geográfico Militar. http://www.zonu.com/argentina_mapas/Mapas_Provincia_Rio_Negro_Argentina.htm 


\section{Breve antecedente del paso de Territorios Nacionales a Provincia}

La Patagonia argentina, como casi la mitad de la superficie del país, se integra a la organización estatal a fines del siglo XIX, subdividida en Territorios Nacionales. Esta figura administrativa implicaba la negación a los habitantes de esos espacios al derecho de elegir autoridades propias y de allí incidir en la definición de los planes de desarrollo que los afectaban, facultad que quedó como potestad del poder ejecutivo nacional y de las decisiones de las cámaras legislativas nacionales (luorno y Crespo, 2008). Esta organización generó dinámicas de integración diferenciada que fueron caracterizadas como economías de enclave (Arias Bucciarelli y Favaro, 2008). En el espacio rionegrino redundaron en la desarticulación progresiva entre regiones aledañas, pues los diferentes núcleos productivos y administrativos se vincularon con el espacio central antes que con las regiones colindantes (Navarro Floria, 2006; Rey, 2005).

La concentración de poblaciones y recursos en ciertos puntos, generó que la dinámica extractiva debilitara la capacidad material de organización de los espacio por fuera de los núcleos estratégicos. Desde este proceso adherimos a la crítica de Hiernaux (2013) sobre lo urbano. El autor discute a la ciudad como mecanismo de integración de la población a la modernidad y base del crecimiento nacional. Señala dinámicas de profundización de penetración de economías capitalistas que se advierten destruyendo las escasas bases económicas de las regiones afectadas a partir de la promoción de la concentración poblacional. En sus reflexiones no cita a la Patagonia, pero la extensa bibliografía del proceso de regionalización diferenciada en el espacio rionegrino abre la mirada de Hiernaux a los territorios del sur.

Lejos de una revisión sobre el modo en que el capitalismo se ha desplegado en la región, la historiografía clásica regional ha tomado las dinámicas migratorias como origen de los desarrollos particulares de la organización provincial (Vapñarsky, 1983; Rey, 2005). El espacio rionegrino durante el período territoriano se describe segmentado en tres centros, en el sud-oeste -zona andina- se destaca el poblamiento de San Carlos de Bariloche, representante de un asentamiento mayormente chileno (que se presenta como germano-chileno por razones más simbólicas que demográficas) y se asocia al desarrollo turístico del Parque Nacional Nahuel Huapi; en el centro-norte, la localidad de General Roca se toma como corazón de la producción frutícola del alto valle, ligada a una migración mayoritaria de italianos y españoles que se caracterizan por la fundación de numerosos núcleos poblacionales; finalmente la localidad de Viedma, en el centro-este de la provincia, constituida como capital administrativa en el período territoriano, se vinculó inicialmente a la producción ovina. Como la misma, a principios del siglo XX, comenzó a perder preeminencia, la relevancia de la localidad fue administrativa antes que productiva, y su carácter se asoció a la migración del sur de la provincia de Buenos Aires (Rey y Vidal, 1975; Vapñarsky, 1983).

Las dinámicas sociopolíticas de los años previos a la provincialización también son un antecedente relevante. El argumento demográfico, justificativo central para el sostenimiento de la figura de los Territorios Nacionales, ya se había perdido en la década de 1930, cuando la población se Río Negro llegó a una cantidad suficiente para avanzar en la provincialización ${ }^{5}$. Sin embargo se decide sostener esta figura en línea con la profunda intervención que comienza a realizar el Estado Nacional en todo el país durante esos años (Favaro y Arias Bucciarelli, 1995). A partir de la década de 1940, en el contexto del gobierno peronista, se incrementa la intervención y la planificación, en el marco de un discurso de ampliación de los derechos cívicos que va a redundar en la provincialización de prácticamente la totalidad de los Territorios Nacionales. Río Negro será uno de los últimos en provincializarse a pesar de su alta demografía. Una de las explicaciones es la escasa penetración partidaria del peronismo, que redundó en un distanciamiento entre la Patagonia y el gobierno central (Ruffini,

\footnotetext{
5 Esto es, que la población tuviese derechos a elegir autoridades propias y nacionales.
} 
2005; Arias Bucciarelli, 2010). Núñez (2015) reconoce en la intervención peronista un ensanchamiento de los quiebres respecto de la zona boscosa andina en el oeste del territorio, en línea con la fragmentación espacial y concentración urbana que se desprende de la nueva reducción del territorio patagónico a recurso, analizada por Navarro Floria (2009). El autor reconoce la incidencia de los planes quinquenales peronistas en la explotación hidroeléctrica e hidrocarburífera sin atención equivalente a las producciones regionales, sobre todo fuera del área frutícola (cuenca de los ríos Colorado y Negro).

Estos antecedentes resultan centrales para el proceso que nos ocupa, dado que la industrialización, sea en la modalidad del peronismo centrada en la industria liviana, o en la propuesta desarrollista posterior que buscó potenciar la industria pesada, toma a la Patagonia como recurso antes que desde sus dinámicas socioeconómicas. De este modo la provincia hereda, por una parte, la fragmentación propia de una organización económica delineada en forma externa, por otra, una desconexión poblacional que se justifica desde lógicas migratorias diversas antes que como resultado de la organización mencionada, y por último la falta de acuerdos en lo político que redundó en quiebres internos, vinculados a las divergencias regionales, que resultaron aun mayores que la enorme inestabilidad nacional de esos años (Abel 2010, $2011)^{6}$.

\section{Río Negro y los planes de desarrollo}

Aldo Ferrer, figura relevante del desarrollismo en la provincia de Buenos Aires (García Bossio, 2012), presenta el planteo económico del gobierno desarrollista de Arturo Frondizi como una serie de políticas

\footnotetext{
6 Tras el golpe de Estado de 1955 se inició un reordenamiento político a partir de la proscripción del peronismo que llevó a que el principal partido permitido, la Unión Cívica Radical se dividiera en Unión Cívica Radical del Pueblo (UCRP) y Unión Cívica Radical Intransigente (UCRI). Estas divisiones se replican en la provincia de Río Negro, donde a su vez la UCRI mayoritaria se dividió en UCRI y UCRI Lista Verde (Abel, 2010).
}

públicas tendientes a la integración de la estructura productiva, al impulsar el autoabastecimiento de insumos fundamentales como la energía y fortalecer la capacidad del país de gestionar el conocimiento en un amplio frente de actividades (Ferrer, 2008). Desde este lugar la Patagonia se presentaba como central en el desarrollo estratégico nacional, no solo por la política relacionada a la explotación del petróleo, fundamental en la gestión de Frondizi, sino por la explotación hidroeléctrica ideada en los ríos de la Patagonia norte, cuya cuenca afectaba a la recientemente formada provincia de Río Negro. En este escenario, la afinidad de la gestión del primer gobernador rionegrino electo, Edgardo Castello, con la política nacional explica el modo en que se delinean provincialmente los objetivos declamados a nivel nacional. Su relación personal con los principales referentes nacionales del desarrollismo, lo ubican como uno de los gobernadores más comprometidos con la gestión de Frondizi (Ruffini, 2014). Es más, plantea un Plan de desarrollo que trasciende su propia gestión, 1958-1962, y se inscribe en los tiempos de gestión del Poder Ejecutivo Nacional, pues se extiende hasta 1964. En su discurso fundacional explicita su confianza en el desarrollo para lograr la unidad, diciendo:

"La constante preocupación gubernamental tiene que abarcar a toda la provincia, cubriendo sin distingos todas y cada una de sus zonas, tanto las que se encuentran en la vanguardia, como las que están rezagadas en su proceso de desarrollo... Los escollos de la distancia, los obstáculos de la extensión, los inconvenientes del aislamiento y las dificultades que presentan los precarios medios de comunicación y transporte, serán superables cuando la inquietud espiritual vaya unida a la suficiente determinación de hacer. El gobierno debe sentirse equidistante, condición que la conducta ha de precisar; ser equilibrado, para que la gravitación de aspiraciones justas y de intereses legítimos determine su acierto; y equitativo, a fin de no caer en el defecto de las preferencias" (citado en Espinosa, 2014: 1).

En 1960, al presentarse el Programa de Desarrollo de Río Negro 1960-1964, denominado PRO-5, Castello señalaba como epígrafe: "El objetivo más alto de mi gobierno es 
lograr el desarrollo armónico de Río Negro" (ME RN, 1960: 5).

Dos términos de esa frase llevan a interrogantes, por una parte, que se entiende por "desarrollo armónico" y por otra, que se asume como "Río Negro", pues ni la dinámica de desarrollo que se propicia ni el espacio de aplicación pueden considerarse como universalmente acordados. Manzanal (1980), desde la caracterización económica del plan, evidencia fuertes sesgos a favor de unas regiones sobre otras, que irían en contra de la idea de "desarrollo armónico" en el sentido de equidad que se desprende de los discursos de época.

La noción de "armonía" repetida en los diferentes discursos y documentos de planificación de la región, se inscribía en una gestión e inversión selectiva, donde legalidad y paz social se presentaban como las condiciones posibles del desarrollo "armónico e independiente" del país (Frondizi citado en Pisarello Virasoro 1996: 16).

Castello se alinea a la mirada nacional, cuando reconoce el carácter dependiente del plan provincial respecto del nacional. Señala que se pretende un alcance de tal magnitud que resulta imposible de llevar adelante "... con fondos exclusivos de la provincia." (ME RN, 1960: 11). Esto inscribe al PRO-5 en una perspectiva de desarrollo más amplia, donde el "...satisfacer objetivamente a reales necesidades de desarrollo local..." (ME RN, 1960: 11-12) se asume contribuyendo "... al afianzamiento de la economía nacional." (ME RN, 1960: 12). Así la equidad se supone en la alineación con la propuesta nacional y ambas escalas se presentan sin roces.

Se asume que el desarrollo no es un proceso autónomo o espontáneo, sino que es la resultante de un esfuerzo deliberado y sistemático de gobiernos, actores económicos y sociedad civil, en pos de opciones económicas técnicamente viables y socialmente equitativas (Bajraj, 2000; Pisarello Virasolo, 2000). El PRO-5 se inscribe claramente en el espíritu desarrollista de los 60, pues se formula en los términos de relevancia social que atraviesan la propuesta de industrialización (Leiva Lavalle, 2012; Ganiza, 2013). Se menciona por ejemplo que el ideal de la economía es "...aumentar el bienestar material de la comunidad [...] alcanzar el ideal humano..." (ME RN, 1960:12) y la armonía como una referencia permanente, tanto en relación a la equidad de la intervención como a la conjunción entre "... la iniciativa privada y el espíritu del progreso..." (ME RN, 1960: 12). Así, el PRO-5 se presenta como la concreción de una planificación que se propuso avanzar en el desarrollo armónico de un espacio atravesado por dinámicas de crecimiento diferentes.

El desarrollismo discute las jerarquías territoriales a escala continental a partir de criticar la idea de ventajas comparativas, desde la teoría de la dependencia (Prebisch, 1998; Bielchowsky, 2010). Dentro del espacio provincial estas nociones se materializan al dividir en "zonas económicas" el territorio (ME RN, 1960:12). Esta división se vinculó a la propuesta de polos de desarrollo de Perraux (Hiernaux, 2013), pues en cada una de las regiones se reconoce una localidad como centro de la intervención estatal ${ }^{7}$.

La crítica que Hiernaux (2013) introduce a la mirada de Perraux por fomentar el deslizamiento de la no ubicuidad del crecimiento puede ayudar a ver las contradicciones que se plantean en esta planificación. El autor indica que la idea de polos de desarrollo se concentra en ciertos nodos de la economía donde aparecen factores de innovación, de allí se infiere una planificación geográfica donde estratégicamente se ubican nodos de innovación sin reparar en las dinámicas extractivas entre los centros poblados y las regiones. Desde el caso de Río Negro esta crítica permite sumar otro matiz, porque la relación entre los polos es en sí problemática, y los sentidos mismos de innovación están en tensión. El esquema que ubica a las distintas Zonas, presentado en la Figura $\mathrm{N}^{\circ} 2$, da cuenta de este lugar de diferenciación por exclusión en la zona históricamente más relegada de la provincia de Río Negro. La Zona V resulta ser un área de no pertenencia a ninguna de las anteriores, con límites definidos a partir del reconocimiento prioritario de las cuatro previas.

\footnotetext{
7 En la Zona I, General Roca; en la Zona II, Choele Choel; en la Zona III, Viedma; en la Zona IV Bariloche y en la Zona $\mathrm{V}$, Ingeniero Jacobacci (ver ubicaciones en Figura $\mathrm{N}^{\circ} 1$ ).
} 
Figura $N^{\circ} 2$

Mapa de las Zonas Económicas delimitadas para Río Negro

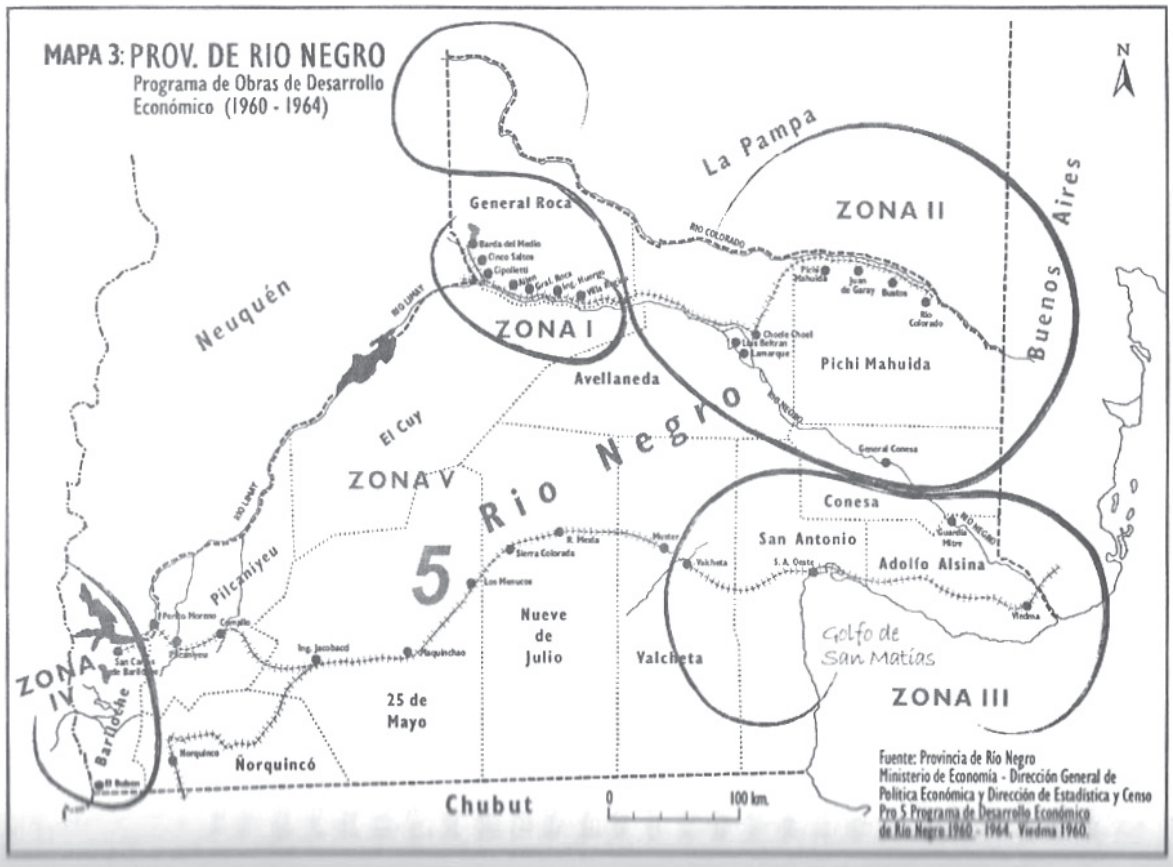

Fuente: ME RN (1960: 21-24)

Los tres centros de crecimiento territoriano (General Roca, Viedma y Bariloche, presentados como los polos en las Zonas I, III y IV) pueden asociarse a una pérdida de atención sobre los aledaños, esto es, las Zonas II y V definidos por el PRO-5. Ahora bien, esta demarcación como antecedente, lejos de desdibujarse, durante la formación de la provincia se redefinió. La Figura $N^{\circ} 3$ grafica la inversión que se plantea para cada zona en esta gestión. La diferencia de fondos pone en evidencia la importancia otorgada a cada sector de la provincia, como parte del desarrollo armonioso que se buscaba llevar adelante.

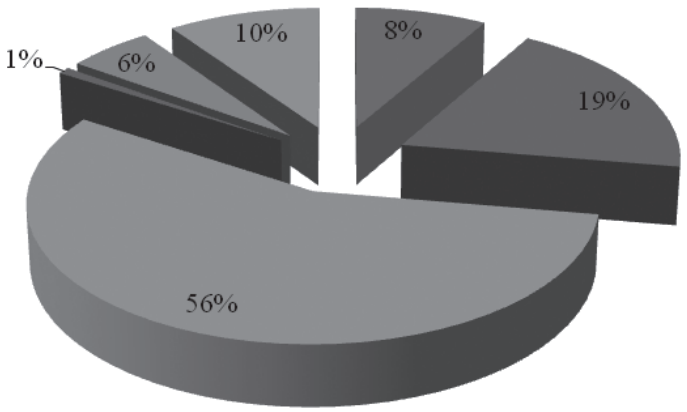

\author{
- Zona I: Alto Valle \\ - Zona II: Valle Medio \\ • Zona III: Atlántica y Valle \\ Inferior \\ - Zona IV: Andina \\ ana V: Meseta \\ - Infraestructura provincial
}

Fuente: Elaboración propia en base a datos del PRO-5 
La prioridad es la Zona III, circundante a la localidad de Viedma, donde se propone el desarrollo del Valle Inferior como respuesta al desarrollo desigual precedente. Esta diferencia se profundiza si sumamos las inversiones previstas en las áreas del Alto Valle (Zona I), Valle Medio (Zona II) y Valle Inferior-Atlánti- ca (Zona III), pues encontramos un $83 \%$ de la inversión general aplicado a la cuenca de los ríos Colorado y Negro. Si reformamos el gráfico, quitando la inversión general provincial, las diferencias generales se acentúan, ubicándose en este espacio el 93\% de las inversiones, tal como se observa en la Figura $N^{\circ} 4$.

Figura $\mathrm{N}^{\circ} 4$

Inversiones regionales estipuladas en el PRO-5

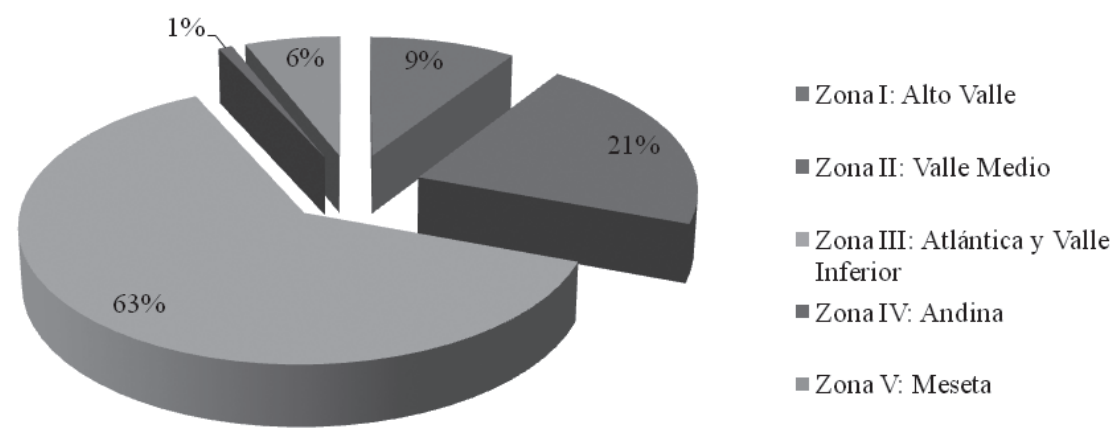

Fuente: Elaboración propia sobre la base de datos del PRO-5

Si pensamos que el total de la provincia tiene actividades agropecuarias, podemos relacionar esta construcción con los antecedentes de inversión del período territoriano, sobre todo en cuanto a la planificación peronista previa a la formación de la provincia, que desde 1947 privilegió la mirada sobre el Valle Medio (Zona II) iniciando un proceso de expropiación de terrenos improductivos y construcción de canales de riego (Perón, 1947). Así inversión desigual del PRO-5 se alinea a una disparidad histórica. En contra del discurso sostenido, repite la falta de consideración al espacio menos atendido (Zona V) y continúa la lógica de inversión delineada los años previos. Algunos de los elementos para justificar esto pueden asociarse a que la planificación sigue respondiendo a diferencias extrarregionales.

Esto se evidencia en la sección III, cuando se indican las "Características del Programa". Allí se señala que se realizará de "...manera conveniente para la economía nacional" lo cual implica excluir "...toda realización [de obras] que no sea de inmediata urgencia." (ME RN, 1960:15).

Las actividades de Río Negro se detallan como agrícolas, frutícolas y ganaderas y otras menos desarrolladas, que se supone serán resueltas con el establecimiento de plantas manufactureras, como lavaderos de lana y frigoríficos. Las obras base para avanzar en una estructura industrializada son las de electrificación, realización de caminos, puentes y la reactivación portuaria. Esto se asocia a la exportación frutícola y las explotaciones mineras previstas en el sudeste provincial, ligadas a ampliaciones en el terreno de la siderurgia y petroquímica en otros espacios del país (ME RN, 1960: 15-16). No se plantea el necesario establecimiento de industrias en el espacio de extracción de recursos. El crecimiento se daría a partir de la ampliación de la frontera agraria, que en función de la inversión antes 
citada planificó la incorporación de seiscientas mil hectáreas irrigadas (Río Negro, 2001). Esto no es menor si se tiene en cuenta que, en la mirada desarrollista, la inversión es base de la construcción espacial.

Pero al interior del espacio pareciera que la sombra de las "ventajas comparativas" permaneció en la estructuración territorial. La idea que la desigualdad es un inconveniente no es tan obvia. La intuición de la desigualdad como motor del crecimiento, esto es, como base de la complementariedad, sostenida desde el más temprano liberalismo y reformulada a mediados del siglo (Hirschman, 1958), puede pensarse pesando en los imaginarios sobre los que se funda el orden territorial rionegrino.

En este punto, la forma en que se caracteriza la iniciativa privada y a las diferentes actividades dentro del territorio permite exponer la trama de sentidos desde la cual se va llenando de significados al espacio.

El PRO-5 al describir los "Objetivos del Programa", indica "...el progreso alcanzado hasta ahora en la Provincia ha sido el resultado tenaz de la iniciativa privada...", siendo las actividades reconocidas como de "seguro rendimiento" la agricultura y la ganadería". En esta consideración no se menciona la actividad propia de la zona andina (la zona IV en el PRO-5), esto es, el turismo. De hecho, en la Constitución Provincial sancionada en 1957, al mencionar las actividades económicas entre los artículos $32^{\circ}$ al $39^{\circ}$, se menciona “... la producción agrícola, la industrial y minera, el comercio y el crédito, así como el trabajo y la propiedad privada, serán consideradas en función social..." (Art. $33^{\circ}$ ). El recorte de lo provincial, esto es, de las actividades y dinámicas asociadas a lo que se entiende como la provincia, queda delimitado a estas iniciativas.

Además de las actividades presentes, la Constitución refiere a los recursos naturales, sobre todo los energéticos (Art. $34^{\circ}$ ) y las actividades comerciales e industriales que se proponen organizar con un sentido regional, para promover la diversificación y aprovechar la ubicación en los espacios de producción de materias primas y energía (Art. $38^{\circ}$ ). El eje del progreso apoyado en el fomento a la industria pesada, propio de los cambios que se busca propiciar, queda en evidencia en el PRO-5 cuando, a las históricas actividades de agricultura y ganadería se agregan "el petróleo, la siderurgia y la energía" como nuevas perspectivas de crecimiento, en tanto y en cuanto "...se acompañen con las obras públicas adecuadas..." (ME RN, 1960: 15).

Ahora bien, aun cuando hay un reconocimiento a recursos básicos para la industria pesada, es claro que la mejora frutihortícola es la marca de crecimiento que propone Castello. La forma en que se delimita lo industrial lo clarifica. La Ley $\mathrm{N}^{0} 138$ de Fomento Industrial, sancionada en 1960, señala: "Artículo $5^{\circ}$.- Las industrias que manufacturen, extraigan, transformen o elaboren artículos y productos en los que se utilice en forma total o parcial materia prima originaria de la provincia y las referentes a la conservación frigorífica, gozarán de exención de los siguientes impuestos ...". Y sigue en relación al modo en que se favorecen los establecimientos industriales. Dada la explícita mención a la utilización de materia prima y la conservación frigorífica, parecería que quienes sancionaron esta ley estaban pensando en una industria basada en el agro y en menor medida la minería.

Esta inversión ponderada nos introduce en un tema central en cuanto a la configuración de una geografía diferenciada, que nos vuelve a la pregunta por desarrollo armónico y por la superación de las desigualdades al interior de la provincia. García Álvarez (2003) repara en el carácter construido y dinámico de las divisiones político-económicas, buscando abandonar la idea que las mismas constituyen presupuesto estáticos, al entenderlas como procesos que involucran determinados reconocimientos a agentes sociales; que impactan en la construcción de identidades, imaginarios y narrativas territoriales. La territorialización de Río Negro, en el período en que se busca implantar un determinado orden político permite enriquecer el reconocimiento de este carácter dinámico.

Al acercarse la finalización de la gestión de Castello, se publica una memoria por iniciativa de la gobernación donde se menciona que

“... se ha obrado con fervoroso espíritu regionalista, en una tarea que ha sido de 
búsqueda y planificación, con realizaciones que, si no han colmado todos los anhelos, quedan para un balance más completo en un futuro próximo, cuando el programa estructurado en este primer ciclo de la autonomía provincial autárquica, se concrete sobre las bases establecidas por este gobierno" (Fantini, 1961: 30).

Este espíritu regionalista tuvo como objetivo el instalar la prioridad de la zona III, que no redundó tanto en el debilitamiento de la zona I, la gran antagónica, sino en la profundización de la invisibilidad de las áreas históricamente desestructuradas del ordenamiento espacial.

Es claro que las zonas IV y $\vee$ quedan fuera de las consideraciones productivas, pero las diferencias se establecen desde argumentos disímiles, cuyas distancias se clarifican en las gestiones posteriores.

\section{Carlos Nielsen y la provincia fragmentada 1964-1966}

El reconocimiento del espacio provincial podría vincularse a los acuerdos y desavenencias políticas, al menos ello es posible para la segunda gestión. Tras el retorno de la democracia con el peronismo proscripto, en 1958, se inauguró el primer gobierno rionegrino. Para las segundas elecciones, convocadas en 1961 se permite la participación del peronismo desde un argumento de legalidad necesaria (Pisarello Virasoro, 1996) y con el supuesto de que una derrota en las urnas debilitaría la injerencia de Juan Domingo Perón desde el exilio (Rapoport et al., 2000). Sin embargo, en Río Negro triunfa la fórmula justicialista. En este escenario se interviene la provincia, se pone fin a la presidencia de Frondizi en 1962, y para 1963 se vuelve a llamar a elecciones, nuevamente con el peronismo proscripto, pero fortalecido respecto del período precedente (Abel, 2010; 2011). En este contexto gana Carlos Nielsen. Su gestión, frente a la débil legitimidad, apeló a una idea unificada de Río Negro que se va a proyectar en la forma de presentar la historia y el territorio.

En 1965, a instancias del gobierno provincial, una organización no gubernamental denominada Cruz del Sur publica "Panorama Provincia de Río Negro", como una síntesis de la visión de la provincia en este período. La redacción romántica de la obra se vincula al estilo que Nielsen impuso en los documentos de gobierno en general y marcan elementos de poética y geografía como bases del imaginario espacial que buscamos problematizar.

Uno de los puntos llamativos de la obra es que se considera a toda la provincia potencialmente productora sin reconocer la desigualdad heredada de las gestiones previas. La zona de la estepa, aun descripta desde su aridez, se reconoce con capacidad para sumarse al espíritu emprendedor que se supone presente. En esta línea, se describe:

"Subiendo desde la baja zona del litoral atlántico, las mesetas escalonadas se adueñan de la Provincia y la cubren casi por completo ... Generalmente está cubierta por una vegetación xerófila, por mantos de piedra o de tierras coloreadas en arco iris, así las tenemos rojas, amarillas, naranjas, verdes, azulinas, ocres, grises, etc.

Tiene su particular encanto, y su frialdad es ahuyentada por los bellos valles y maIlines, que albergan su mejor vegetación, signo de que la tierra no es estéril, sino que le hace falta la hermana agua y la mano del hombre que la haga fecunda " (Cruz del Sur, 1965: 7-8).

La imagen omite la inversión desigual o la referencia a procesos de concentración. En esta gestión las divisiones internas se redefinen, en línea con el argumento de similitudes que se sostiene desde el discurso institucional. Los nuevos límites responden a nuevos criterios. La organización política que se define no responde a las Zonas económicas previamente planteadas, sino que se agrupan en cuatro regiones, asociadas a la división departamental (ver Figura $\mathrm{N}^{\circ} 1$ ).

La Región I queda circunscripta al Departamento de General Roca. La Región II, contiene los Departamentos de Adolfo Alsina, Avellaneda, Conesa y Pichimahuida. La Región III, con los Departamentos de 9 de Julio, Valcheta y San Antonio, y finalmente la extensa Región IV, agrupando Bariloche, El Cuy, Ñorquinco, Picaniyeu y 25 de Mayo (Cruz del 
Sur, 1965, 26-27). Esta agrupación vuelve a repetir la visión sesgada que el PRO-5 había explicitado. Con algunos detalles, las Regiones I, II y III corresponden con las zonas económicas precedentes, con la excepción de la introducción del Departamento 9 de julio en la Región III, claramente perteneciente a la Zona $\mathrm{V}$ en el Plan de Castello. En la Región IV, se ensamblan las Zonas económicas IV y V. La posibilidad de esta integración políti- ca en espacios con lógicas administrativas tan diferentes, da cuenta de una elección desigual en relación a la prioridad en el desarrollo de la amplia geografía provincial. La concentración de juzgados y policías en la Región 1, mapeados como parte de la descripción, vuelven a poner en evidencia las asimetrías de una mirada que, en términos de planificación, no se concibe con sesgos (ver Figura $N^{\circ} 5$ ).

Figura $\mathrm{N}^{\circ} 5$

El Río Negro político en la gestión de C. Nielsen

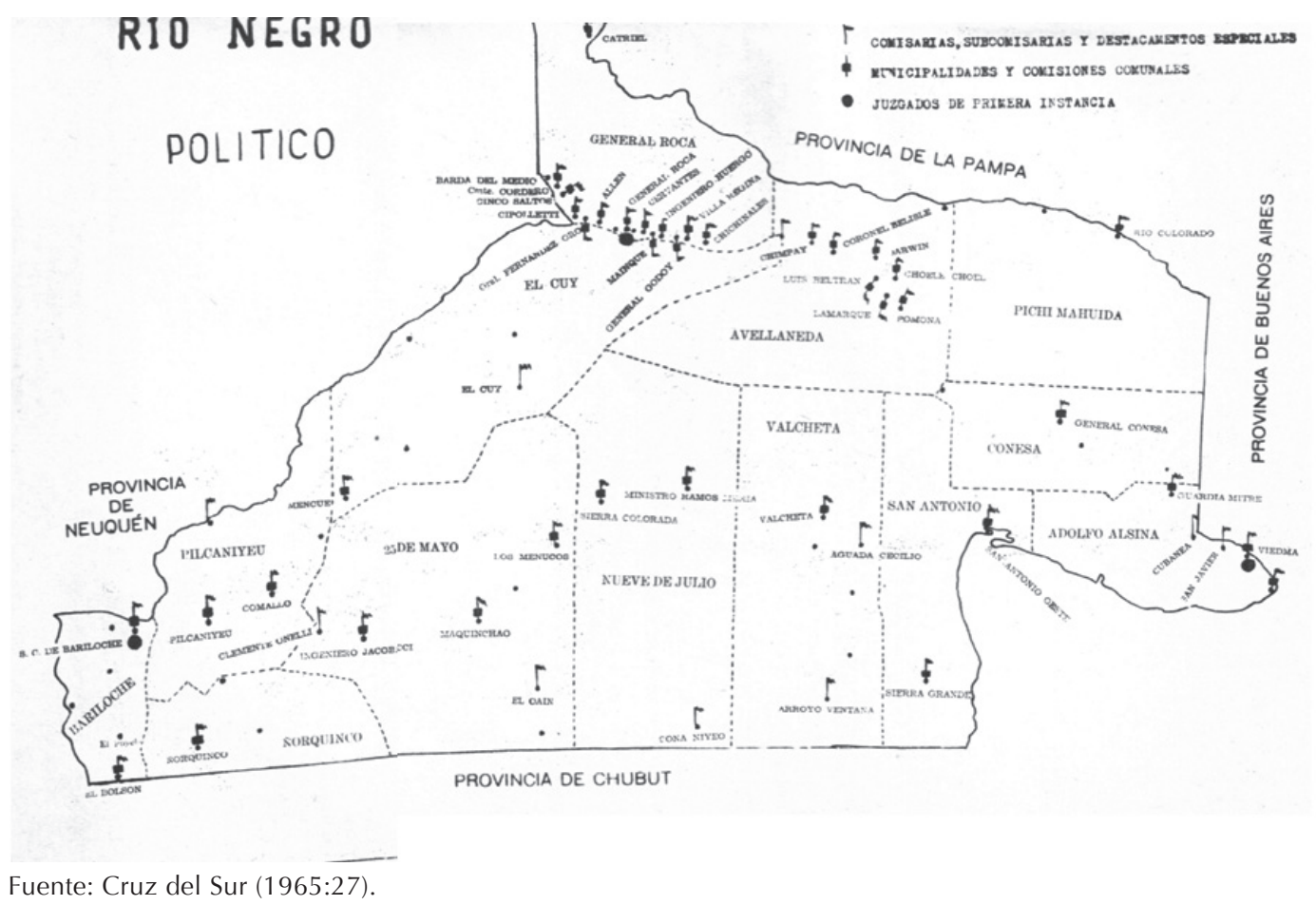

Los sucesivos mapas que ilustran esta obra permiten reconocer este aspecto de equidad supuesta como parte de las valoraciones en la interpretación del espacio. Por ejemplo, que toda la provincia se grafica como productiva, a pesar que la agricultura altovalletana (Región I), es tomada como el "Factor del éxito" de la provincia (Cruz del Sur, 1965: 74) o el río Negro presentado como "La columna económica de la provincia y el más grande río Patagónico" (Cruz del Sur, 1965: 30).
Aun con una retórica de unidad, el gobierno repite el imaginario del "motor del cambio" en la estructura histórica. Reincide entonces en la valoración diferenciada del espacio y el reconocimiento de dos lógicas provinciales en una misma unidad administrativa. Lo que podríamos denominar "la provincia del desarrollo", con procesos de crecimiento específicos y legislados, y "la provincia del paisaje", sin necesidad de mayores intervenciones. 
La armonía a construir de Castello, con Nielsen deviene en la armonía de hecho existente en el territorio. Todo es promesa y posibilidad, y en esta negación de las contradicciones sobre el modo en que se está dando el crecimiento, se reproduce un reconocimiento desigual que va a generar un incremento en la atención sobre los espacios centrales, en una mirada que incluso se va a profundizar en el golpe de Estado posterior a esta gestión (1966-1973). De hecho, los estudios de las grandes puebladas en el Alto Valle, el cipoletazo en 1969 (Tapia, 2012; Fedelli, 2011), y el rocazo en 1972 (Yappert y Bohoslavsky, 2012; Favaro et al. 2010), se interpretan a partir de modelos de desarrollo provincial que se discuten entre dos localidades de la Región I. El primero de estos movimientos tuvo que ver con la conectividad interna, la pavimentación de la ruta 6, que uniría General Roca y Bariloche por localidades rionegrinas como Paso Córdoba, Chasicó e Ingeniero Jacobacci (ver Figura $N^{\circ} 1$ ). El debate por el cual se dejó de lado este proyecto tuvo que ver con los beneficios que estrictamente afectarían a Cipoletti o a General Roca, sin mayores referencias a la conexión que significaba esta iniciativa ${ }^{7}$. Es interesante la falta de fundamentos en relación a la vinculación interna. Podríamos pensar que el territorio que queda por fuera del las cuencas de los ríos Colorado y Negro queda subordinado, pues sus intereses se presentan como exteriores a sí mismos.

Los caminos y vínculos comunicacionales son instituyentes de imaginarios espaciales e identidad (García Álvarez, 2003). En el espacio que nos ocupa, la falta de atención a lo denominado como "la provincia del paisaje" se tradujo en un limitado acceso de rutas, servicios y vías de comunicación.

Es interesante como las perspectivas que se grafican como horizonte de futuro en 1965 repiten este esquema de desconexión (ver Figura $N^{\circ} 6$ ). Donde las obras se concentran en "la provincia del desarrollo" y para el resto del espacio no se plantean caminos, sino obras parciales que tienen que ver con dinámicas extractivas como la minería. El relato va profundizando la regionalización en clave desigual.

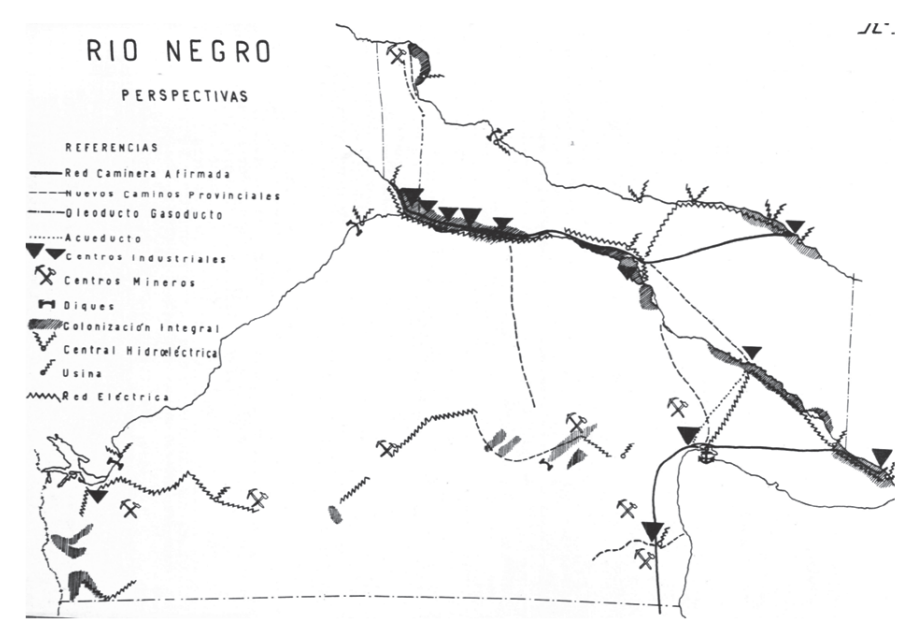

Fuente: Cruz del Sur (1965: 207).

\footnotetext{
7 Un detalle de este conflicto puede verse en Tapia (2012), quien recorre los argumentos. El resultado del enfrentamiento fue una pueblada en Cipoletti, localidad que se oponía al proyecto), que redundó en un cambio en la gobernación en un período de
}

facto. El "rocazo" de 1972, tuvo que ver con un levantamiento popular en relación al sitio de asentamiento de juzgados provinciales (ver Yappert y Bohoslavsky, 2012). 
Siguiendo a García Álvarez (2003) "Cada tipo de división entraña, habitualmente, un modelo de sociedad específico; o a la inversa, cada cambio en la estructura social del poder suele propiciar el cambio de la malla político-administrativa" (García Álvarez, 2003: 72). No se trata de un ejercicio determinista, sino de reconocer el peso de las influencias, que en este caso profundizan órdenes heredados allí donde argumentan instalar un cambio.

En este punto es interesante referir la construcción espacial a una actividad especialmente afectada en este período, el turismo. Decíamos, en relación a la gestión previa, que el ordenamiento original de la provincia no lo había tenido en cuenta, a pesar de ser el eje económico de uno de los centros de mayor población. Pero en el gobierno de Nielsen esto cambia. En la retórica de unidad con que presenta Río Negro, toda la provincia es tomada como turísticamente interesante. Lo turístico está "dado", tal como se infiere del siguiente párrafo, y no precisa de mayores intervenciones:

"El Todopoderoso ha derramado sobre RíO NEGRO los dones maravillosos de la belleza casi 'a manos Ilenas'; ella puede ser hallada desde un extremo a otro de la Provincia, en una gama de recursos que encanta a todos los espíritus amantes de lo estético, de lo majestuoso, de lo plácido, de lo recóndito, de lo pequeño o de lo inmenso, todo lo que al hombre pueda resultarle atractivo... [en Río Negro] se han establecido las condiciones para que todos los habitantes de la misma y los que deseen visitarla, encuentren las comodidades estiladas de esta moderna y exigente actividad" (Cruz del Sur, 1965: 169).

Este argumento permite omitir la necesidad de planificar en esta actividad y en esta área, porque aun cuando lo agroproductivo también se grafica otorgando a todo el territorio la misma importancia, la planificación regional precedente repite la lógica por la cual los valles andinos no tienen la misma relevancia que las cuencas tomadas como centrales. Podríamos pensar que territorio y actividad se deslizan en la construcción de sentidos, lo andino es turístico, aunque eso apele solo a una localidad.
En 1964, Jesús Dionisio Fanjul relataba en un pequeño libro publicado, además, en el principal medio de prensa provincial, el diario Río Negro, el problema del desarrollo de Bariloche. La recurrente reflexión a la falta de lugar en una legislación que permita diseñar política asumiendo al turismo como actividad económica remite a la construcción social del turismo, consolidada en el período justicialista, y con permanencia en los años que nos ocupan (Núñez y Vejsbjerg, 2010). De hecho, a la luz de la legislación que se define esos años, podemos pensar que es más una actividad relacionada con el ordenamiento político que económico.

La ley de Turismo de Río Negro, sancionada el 28 de octubre de 1964 tiene varios puntos que permiten esta lectura. En el artículo $2^{\circ}$ encontramos: "Declárese de interés turístico todo el territorio de la Provincia". Esta generalización de la actividad turística se retoma desde diferentes ángulos, por ejemplo el artículo $3^{\circ}$ se indica: "... Proyectar las disposiciones adecuadas para la organización del centro turístico considerando sus caracteres naturales termoclimáticos, históricos, culturales y folclóricos...". De la misma manera en el artículo $8^{\circ}$ se señala “... Establecer para todo el territorio de la Provincia, las categorías en que habrán de clasificarse los hoteles, restaurantes, hosterías, residenciales, moteles, alojamientos, fijar sus requisitos esenciales y dictar sus normas reglamentarias...". El espíritu declamado en "Panorama Río Negro" se establece en relación al turismo más que cualquier otra actividad.

La Ley de Turismo tiene un importante impacto material, pues afecta la dirección de los recursos para el desarrollo turístico. A diferencia de la gestión precedente, durante estos años hay referencias a importantes mejoras en la infraestructura turística de la mano de la provincia. La ley $\mathrm{n}^{\circ} 414$, sancionada en 1965, señala “... Destínese la suma de sesenta millones de pesos moneda nacional ( $m \$ n$ 60.000.000), para el Plan de Fomento Hotelero, Obras y Promoción Turística; fondo que será administrado por el Banco de la Provincia de Río Negro. .." debe mencionarse que no necesariamente beneficia a la zona andina o a San Carlos de Bariloche, porque a diferencia del resto de las actividades, el turismo no se presenta con un carácter regio- 
nal. Podemos pensar en la existencia de una ilusión del desarrollo del turismo en la región andina como resuelto, que se desliza hacia otras consideraciones, al punto de permitir suponer que el desarrollo de la ciudad/región no amerita el diseño particular de ninguna política de innovación.

Otro aspecto a destacar de la actividad es que la mirada de la provincia hacia lo que entiende como atractivo, va a focalizar los centros valletanos. El esquema de atractivos presentado por Nielsen (Figura $\mathrm{N}^{0} 7$ ), va a tener como resultado, en la siguiente gestión democrática, el reconocimiento de áreas de interés en los valles (Alto, Medio e Inferior), más la zona andina, que se repite como ya resuelta (Figura $N^{\circ} 8$ ).

Esquema del turismo rionegrino en la gestión de C. Nielsen (1964-1966)

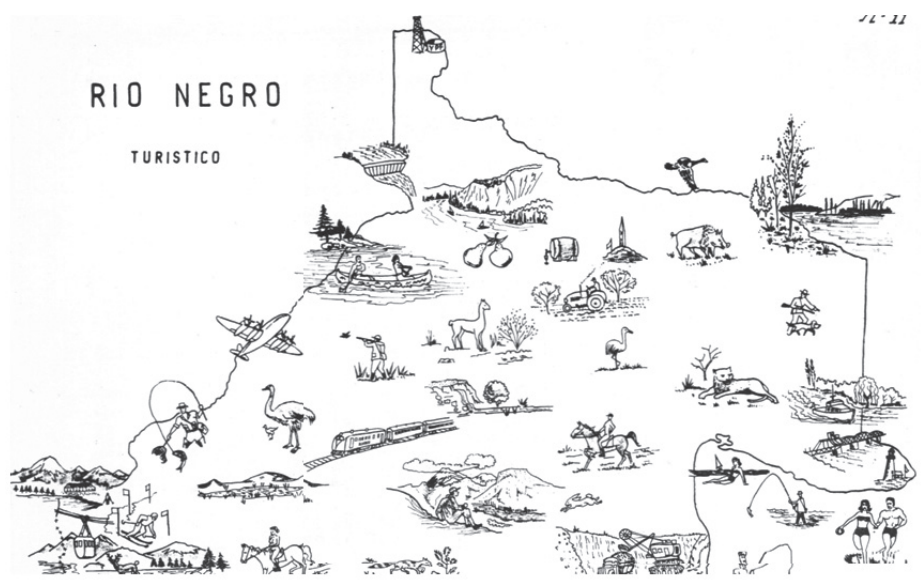

Fuente: Cruz del Sur: (165: 168).

Figura $\mathrm{N}^{\circ} 8$

Esquema del turismo rionegrino en la gestión de M. Franco (1973-1976)

\section{RUTAS QUE INTEGRAN LOS CIRCUITOS TURISTICOS DE RIO NEGRO ${ }^{27}$}

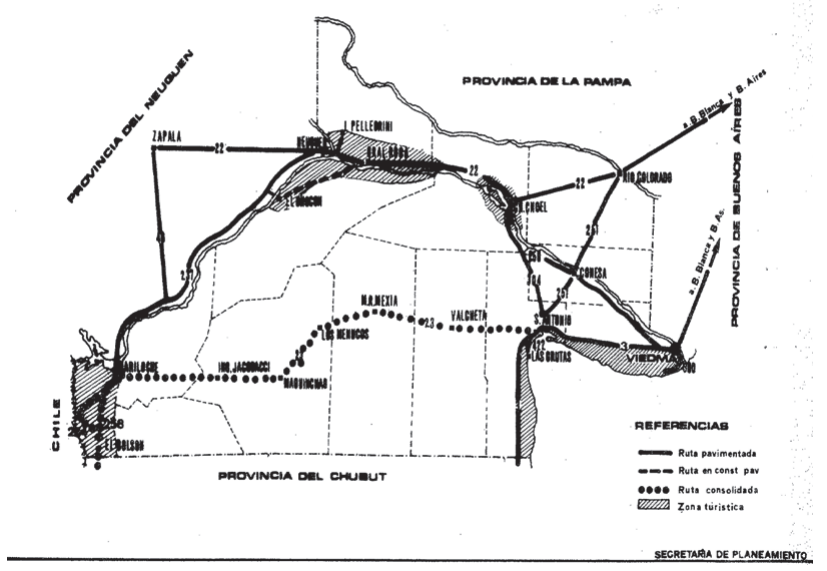

Fuente: PE RN (1973: 280). 
El golpe de Estado entre ambas gestiones ${ }^{8}$ no es menor para comprender esta resignificación espacial. Ya en 1967, las fuerzas públicas de Bariloche apelan a los medios de prensa para pedir que los fondos de turismo generados en la ciudad queden, al menos, en la región (Río Negro, 1967). Sin embargo, en 1968 es claro que este reclamo es contrapuesto a la política provincial, cuando se traslada la Dirección Provincial de Turismo de Bariloche a Viedma porque "...dificulta el desarrollo de la política que en la materia encara el Gobierno." (Dto 841/68). El resultado será el mapa de 1973 (ver Figura № 8), donde lo atractivo a construir se superpone a los centros promovidos.

\section{Mario Franco, el gobierno justicialista y El Plan Trienal 1974-1976}

Con Mario Franco, en 1973, se inicia el primer gobierno justicialista de Río Negro, que tomaremos como el último de este período constitutivo provincial, en vista al impacto del golpe de Estado iniciado en 1976. Este gobernador, en línea con el Estado Nacional, elabora un Plan Trienal que adapta la planificación general a la dinámica rionegrina. Este Plan, como parte de la recuperación de la práctica partidaria justicialista proscripta hasta la fecha, tiene un punto de partida diferente a los documentos analizados. Por ello, aun con la continuidad desarrollista del gobierno que se inicia en 1973, se podía suponer la apertura a una reconsideración geográfica alternativa. El Plan Trienal elabora una crítica al modo en que se había resuelto el desarroIlo nacional previo, indicando la histórica inequidad en la atención al desarrollo en la Patagonia. Sin embargo, en el proceso de analizar el modo en que se ha edificado esta desigualdad, vuelve a repetir esquemas de desarrollo que terminan siendo justificativos del centralismo, al atar el desarrollo local a un proceso nacional.

8 En 1966 se lleva adelante un golpe de Estado, cuya administración se extiende hasta 1973. En esos años, el Poder Ejecutivo Nacional estuvo en manos de Juan Carlos Onganía (1966-1970), Roberto Levingson (1970-1971) y Alejando Lanusse (19711973). En Río Negro, en el mismo período se sucedieron seis gobernadores, José Fasseri (1966-1966); Carlos Uhalde (1966-1966); Luis Lanari (19661969); Juan Figueroa Bunge (1969-1969), Roberto Requeijo (1969-1972) y Oscar Lava (1972-1973).
Al ser este un gobierno justicialista podría pensarse que la sobrevaloración del período del peronismo histórico opera como una legitimación a la propuesta. De hecho, la legitimación en clave partidaria, se explicita en la valoración sobre el modo en que se fue estableciendo lo que se entiende como la equidad distributiva en el espacio. Así, tras una crítica al desarrollo general en clave de dependencia hasta 1945, se indica el cambio que introdujo el peronismo histórico, señalando que "La Patagonia comenzó a articularse con el resto del país a través de las políticas del Primer Plan Quinquenal (1947-1951)" (PE RN, 1973:3). Antes y después, se refiere al modo en que el desarrollo avasalló los intereses regionales. Sin embargo, a pesar de mencionar la intensión de los planes justicialistas por cambiar las condiciones estructurales de inequidad, el documento destaca como obra fundamental al gasoducto entre Comodoro Rivadavia y Buenos Aires, permitiendo repetir la lectura de dependencia en lo que Navarro Floria (2009) presenta como colonialismo interno, pues se consolida la estructura de servicios que fomenta la concentración poblacional sobre el desarrollo provincial. La mirada de Franco, que disculpa elementos de centralismo en clave partidaria, introduce elementos geográficos como explicación de desigualdades.

En los argumentos del Plan de 1973 hay una crítica explícita al modo en que se ordenó territorialmente la Patagonia, sobre todo a partir del quiebre que implicó el reconocimiento impositivo diferenciado al sur del paralelo $42^{\circ}$ en la década de 1960 . Esta división patagónica es el argumento inicial para mostrar lo que el gobierno de Franco entiende como el resguardo de intereses espurios que afectaron el crecimiento provincial.

"Estos intentos de establecer nuevas divisiones territoriales se desarrollaron durante la vigencia de gobiernos centralistas, producto de los golpes militares de la década del '60" (PE RN, 1973: 4).

El modo en que se denuncia esta división interna en lo Patagónico resulta Ilamativa a la luz de que no se repara en los quiebres internos en el desarrollo provincial, que como vimos se desprenden de la desigualdad en la inversión de acuerdo al esquema establecido 
por Castello, que es la gestión que discute Franco. Las impugnaciones son en relación a las vinculaciones supraprovinciales y en esto nos remite al planteo desarrollista, que no utiliza una mirada crítica equivalente en las relaciones internas y externas. En el Plan Trienal, la desigualdad provincial, antes que en las políticas de desarrollo, se justifica en la geografía que se describe. De esta manera, el determinismo geográfico se filtra en la reflexión de 1973. Esta lectura puede reconocerse en la forma de considerar al centro-sur provincial, esto es, la región que de Zona $\mathrm{V}$ pasa a parte de la Región IV en los ordenamientos previos. En relación a la misma, el documento de Franco indica:

"Zona Centro Sur - Ganadería ovina

Nuestra provincia, al igual que las que componen la región patagónica debe necesariamente orientar extensas áreas de su territorio a la explotación ganadera ovina.

Las características climáticas, ecológicas, la pobreza de los campos en íntima relación con la escasez de lluvias de toda la zona ubicada al sur del río Negro ... impide a la llamada zona sur alternativas de producción distinta a la que se están desarrollando actualmente: es decir la cría del ovino y para circunscribir aun más el carácter de la pro- ducción, se debe mencionar la orientación lanera - que necesariamente tienen y deben tener las majadas" (PE RN, 1974:166)

Son el clima y el suelo, y no la falta de inversión, los argumentos que en esta planificación reducen las posibilidades de acción en el área. Así la geografía provincial puede pensarse como resultante de las políticas que se planifican. Pero esta dimensión construida se oculta tras una visión que va a ir homologando gobierno a gobierno, el paisaje al destino. No se plantea la posibilidad de riego, aun cuando en la cuenca del río Limay se están planificando los lagos artificiales más grandes del país. Tampoco se plantea la actividad de pasturas, a pesar de los antecedentes en la región (López, 2014). El paisaje es el argumento de la ovinización, en detrimento del reconocimiento de potenciales cambios en las dinámicas de producción, o en modificaciones concretas que incidieron en el desmantelamiento de otras producciones, como la alfalfa cosechada históricamente en valles de la estepa, cuya disminución se explicita en los textos educativos financiados por la provincia, donde el incremento en la fruticultura es la evidencia de la mejora (ver Figura $N^{\circ} 9$ ), en directa simetría a los planteos de 1958.

Figura $\mathrm{N}^{\circ} 9$

Caída de la producción de alfalfa respecto de otras producciones

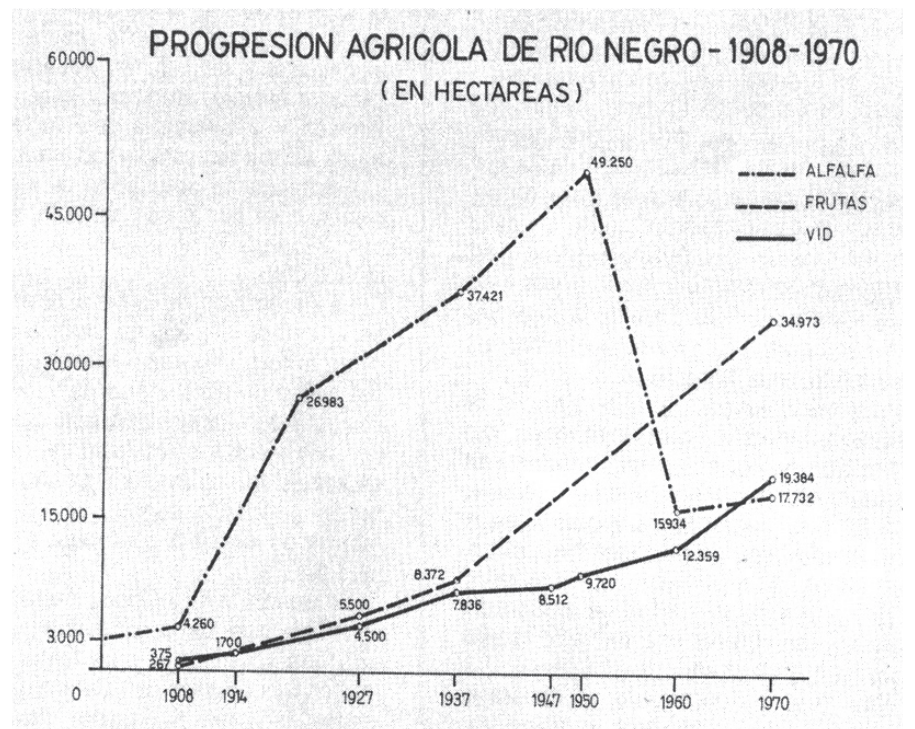

Fuente: Rey y Vidal (1975: 121). 
En el Plan Trienal, la crítica se dirige a la conformación de la región Comahue ${ }^{9}$, y su incidencia en los cambios en las relaciones interprovinciales de la Patagonia continental, al respecto se señala:

"La creación de la Ilamada Región de Desarrollo Comahue ha tendido a desarticular a las Provincias Patagónicas y vulnerar el espacio geográfico-económico en que se hallan insertas desde su origen. Por otro lado, favorece la primacía que sobre el resto del "Comahue" tiene la ciudad de Bahía Blanca y su zona de influencia. Finalmente, en el aspecto cultural, la balcanización de la Patagonia tiene su indicador más evidente en la organización de la educación terciaria" (PE RN, 1974: 5).

El Plan sigue en este tono, discutiendo los elementos del desarrollo general del período previo, pero sin reproyectar esos elementos en una nueva comprensión del espacio provincial. La no discusión de la geografía se puede asociar a que este Plan Trienal está atravesando la legitimación partidaria sobre las dinámicas de desarrollo a considerar. En su reclamo partidario va a presuponer homogeneidades que permiten la idea de un ser patagónico peronista, que ocultan o naturalizan las diferencias espaciales. El lenguaje gráfico del Plan es permanente, pero antes que a referencias ubicadas en la geografía, apela a estadísticas y niveles de frecuencia, de modo que lo provincial se presenta desde dinamismos de crecimiento separados de su referencia espacial inmediata. Las cartografías son escasas, se utiliza la presentación del área provincial en el detalle de la ubicación de los gabinetes psicopedagógicos (PE RN, 1974: 57), en la presentación del detalle de la exportación de manzanas, como el gráfico de la salida de Río Negro al mundo (Figura $\left.\mathrm{N}^{\circ} 10\right)$

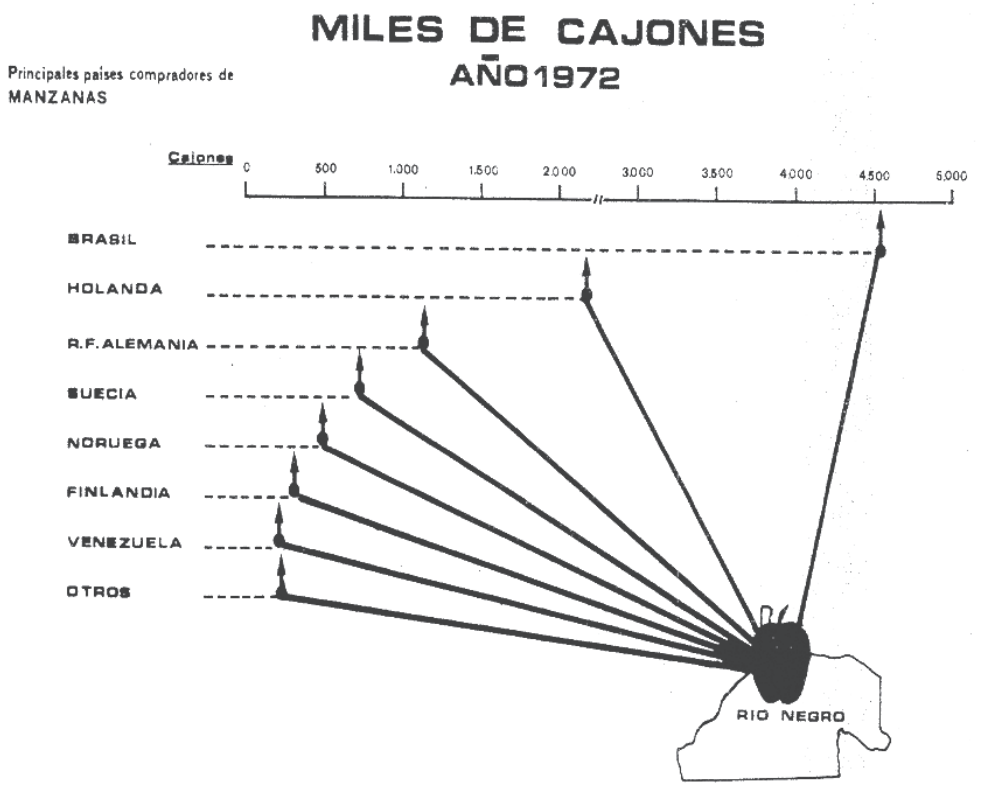

Fuente: PE RN (1973:264)

\footnotetext{
9 Esta regionalización corresponde al ordenamiento del desarrollismo. El Comahue, a grandes trazos, corresponde a la región norte al paralelo $42^{\circ}$, involucrando las provincias del Neuquén, Río Negro y
}

parte de La Pampa y Buenos Aires, en una delimitación que fue muy problemática y cuyo detalle fue recorrido por Arias Bucciarelli (2007). 
El otro esquema espacial que se destaca es el de las rutas y espacios turísticos (PE RN, 1973: 280), el detalle de la infraestructura aérea PE RN, 1973: 359) y la cobertura de radio y televisión (PE RN, 1973: 367). El detaIle cuantitativo no permite, sin embargo, una lectura directa sobre las inversiones, dado que no hay un detalle ordenado en este sentido, sino una valoración sobre la capacidad productiva que busca reiterar la primacía de la región construida como de desarrollo en las gestiones previas. De aquí podemos pensar que, aun planteando una oposición respecto de las políticas precedentes, se repite el esquema de jerarquía territorial.

El peronismo histórico, los gobiernos antiperonistas que lo siguieron, e incluso la recuperación de este signo partidario en la gobernación, fomentaron quiebres y diferencias que redundaron en imaginarios geográficos de aval a la desigualdad. Cuando en 1973, el peronismo rionegrino discute el orden geográfico, mira dos límites que ya habían sido revisados. Critica el establecimiento del paralelo $42^{\circ}$ por no asociarse a regiones económicas, sociales o biográficas ${ }^{10}$. Asimismo denuncia un ordenamiento a favor de intereses centrales exógenos que establecen la región Comahue, cuya delimitación claramente introdujo en la norpatagonia intereses de desarrollo de regiones pampeanas y bonaerenses, abriendo un acalorado debate (Arias Bucciarelli, 2007).

Paradójicamente, aun cuando se critica la perspectiva e intervención centralista, podría pensarse que la misma se repite vista la permanencia de la valoración desigual y la apelación a la autoridad nacional como argumento de orden local. Lo provincial, visto desde las desigualdades, no se observa como resultante de esa intervención, y entonces no se considera como parte de las deudas a resolver.

El esquema delineado por Castello se repite gestión a gestión, y nos ubica una y otra vez en las regiones afectadas por la falta de atención, que desde la construcción admi-

\footnotetext{
10 Un antecedente a esta crítica se encuentra de Rodríguez Meitín (1960).
}

nistrativa parecerían situarse en lo menos rionegrino del crecimiento provincial. $Y$ en este punto es importante pensar en la ganadería como una actividad que resume las paradojas del crecimiento en los tres períodos. En el PRO-5, a pesar que la ganadería es una de las actividades mencionadas reiteradamente, el fomento ganadero que plantea para la Zona $\mathrm{V}$ es del $0,2 \%$. La ganadería ovina no fue un tema para la provincia a pesar de que se lo declama, e incluso a pesar de la pretensión de articulación con el orden nacional que se repite en los discursos.

El alineamiento encuentra un límite en lo ovino y esto se observa en el modo en que una de las principales agencias tecnocientíficas nacionales, el Instituto Nacional de Tecnología Agropecuaria (INTA) dialoga con el estado Provincial desde el centro ubicado en Bariloche. Desde la formación del INTA, en 1958, se plantea un centro nacional de investigación y promoción de la actividad lanera en Patagonia. El mismo se crea y, desde 1965 se ubicó en San Carlos de Bariloche. Pero esta iniciativa nacional no se articuló con ninguna actividad de desarrollo provincial en los años que nos ocupan, aunque sí lo hizo con Chubut, Santa Cruz y Tierra del Fuego (López, 2014).

El gobierno de Franco va a repetir una territorialidad escindida que no discute, y que no solo se estableció por los órdenes provinciales, sino también por la construcción tecnocientífica nacional. López (2014) recorre el detalle de instalación del INTA en el espacio patagónico con cabecera en San Carlos de Bariloche. La autora muestra que, desde esta institución, y por el programa ovino, la Patagonia fue dividida en dos sectores, la Patagonia del riego, asociada a las cuencas de los ríos Neuquén, Negro y Colorado, con una producción en diálogo con el INTA Alto Valle, ubicado en la localidad de General Roca denominada "región rionegrense", y el espacio de secano, el de la oveja, denominado "región patagónica" cuyo mapa se muestra en la Figura $N^{\circ} 11$.

La distinción del INTA divide en dos a la región Comahue, dando lugar al reconocimiento de la pluralidad de sentidos en el área y a la superposición en las planificaciones (Benedetti, 2009). Pero el punto a destacar 
de esta división es que lo Patagónico, como separado de lo irrigado se descubre, en la provincia de Río Negro, también separado de lo productivo. El plan científico-ovino que se Ileva adelante en los sesenta y setenta va a mirar a los grandes productores de los territorios de Chubut, Santa Cruz y Tierra del Fuego.
En Río Negro, las pocas grandes estancias también van a ser acompañadas en su desarrollo, pero la enorme cantidad de pequeños productores quedará fuera de consideración en el diseño de este modelo de desarrollo, en directa relación al reconocimiento que se proyecta desde el Plan Trienal.

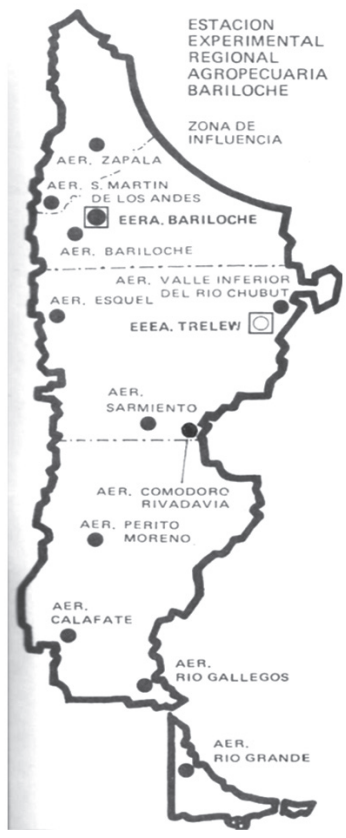

Fuente: Rodríguez (1982:53).

EI INTA Bariloche no dialogará con la provincia hasta avanzada la década de 1970. Podría pensarse que su actividad no es de interés para el desarrollo de lo provincial. Es muy diferente la vinculación provincial con el INTA Alto Valle. Este centro es espacio de consulta y articulación permanente en la provincia (Jong, 2008), con lo cual es la actividad y el espacio delineado a tal fin lo que opera en las distancias o acercamientos administrativos. De este modo, una intervención nacional de gran envergadura, tanto por los montos implicados como por el carácter innovador de la iniciativa quedan, en Río Negro, como ejecutores de fragmentaciones internas.

\section{Reflexiones finales}

A la luz de lo expuesto podemos pensar que la marginalidad no es solo el resultado de la falencia o la pobreza, es construcción de un orden geográfico que proyecta luces y sombras con lógicas variadas. En su análisis sobre imaginarios geográficos, Zusman (2013) introduce elementos vinculados a este dinamismo de construcción de los espacios y de sus márgenes. Geografía y poesía se van a relacionar cada vez más en la reflexión sobre la construcción del conocimiento del espacio, abriendo la incorporación en la comprensión del territorio a la experiencia 
estética, a la historia en la relación con el entorno y a la imaginación, como elemento repetido en estos ejercicios de interpretación. Estos elementos son constitutivos de un orden desigualmente armado que se presenta como natural. Las zonas IV y $\mathrm{V}$ son el resultado de una provincia que, en nombre de la armonía, se asume diferenciad. Con el argumento de las carencias de la zona $\mathrm{V}$, se ignora la zona IV y se fortalece la zona III.

La observación de lo rionegrino nos abre una pléyade de debates. Primeramente, la permanencia en la construcción de las regiones nos permite entender a la categoría de región como en cambio permanente, pasando en el PRO-5 a ser denominada "Zona". Esto implica avanzar sobre las dimensiones relacionales asociadas a lo económico (Bandieri, 2006), pero sobre todo en el armado de un imaginario geográfico, en diálogo con dinamismos políticos, que se enraízan en prácticas cultuales y jerarquías de reconocimientos en diversos órdenes que redundan en la permanente reelaboración de mitos de escisión y diferencia.

La memoria se reescribe como parte de la constitución de la provincia, en un ejercicio que de hecho se va a incrementar en los períodos de golpe de Estado (Núñez, 2007). De aquí, y apelando a la idea del establecimiento de marcos sociales de la memoria, vamos a encontrar en estos procesos de construcción geográfica el anclaje de la memoria colectiva a un paisaje que, desde la fijeza con que se lo presenta, deja por fuera de lo "rionegrino", a vastas áreas, permanentemente incorporadas como desiguales.

Las diferencias políticas solo van a profundizar este ejercicio, apelando a la geografía fija como referencia de la verdad última en contextos de disputa. La no observación de las fronteras internas, en los documentos analizados, nos permite inferir la artificialidad del orden hegemónico, así como la relevancia de su problematización en el ejercicio de comprensión de las dinámicas desplegadas en este espacio. La artificialidad de la imposición de un orden desigual podría ser un resultado esperable, pero el modo en que necesita construirse la geografía en función de las distintas dinámicas de ocultamiento no lo es tanto.
Esto resulta relevante tanto para el análisis de la política del período como para la historiografía que, descansando en los principales actores económicos, ha mostrado limitantes. La agencia económica de numerosos actores se eclipsa en el reconocimiento de lo desigual, de modo que repetir estudios sobre las estructuras prioritarias hace perder de vista la desigualdad estructural del orden y analizar en esta línea, un punto especialmente señalado por Fernández et al. (2012) al indicar las falacias de elaborar conclusiones desde casos exitosos.

Las divisiones, en los sucesivos planes, e incluso en la historiografía regional, se han observado como independientes a la política, casi como marcas autoevidentes a partir de las cuales, y no hacia las cuales, se planifica. En los documentos analizados se repite la ausencia a la carga que implica la delimitación de una diferencia y no se reconoce el tipo de diferencias que se está instituyendo.

Podemos pensar que, a partir de desconocer la consolidación de un territorio escindido en una unidad administrativa, formando parte de la construcción de relatos, anclajes identitarios y establecimiento de políticas, se fueron levantando fronteras internas, argumentadas desde un paisaje que se utilizó para ocultar este establecimiento. La falta de reconocimiento a esta carga permite repetir la paradoja en gestiones de ideologías diversas, donde se incluyen críticas en términos partidarios pero no se revisa la construcción regional.

Como síntesis del período, queda una mirada que cercena la posibilidad del reconocimiento desigual como resultante del crecimiento, un problema presente en las políticas actuales. Lo ovino sigue en crisis, el turismo sigue diferenciándose entre un turismo para los rionegrinos en la costa, y un turismo ajeno en las montañas. La producción frutícola de los valles irrigados sigue dependiente de coyunturas (Bendini y Tsakoumagkos, 2012). La cotidianeidad queda entrampada en las naturalizaciones. De allí inferimos que las diferencias territoriales se vinculan al establecimiento de fronteras separadoras de espacios que se construyen como antagónicos, y desde el diseño de lógicas de apropiación que tienen que ver con la consolidación de 
claves identitarias que se remiten a la particular interpretación que se hace del paisaje. Así, las construcciones desiguales al interior de la provincia de Río Negro aparece formando parte de una trama de asimetrías amplia y compleja, instituida en un horizonte de sentidos comunes que aun se presentan como un desafío a desmantelar.

\section{Referencia bibliográfica}

ABEL, J.L. La UCRI de Río Negro 1958 1963: Partido, elecciones y gobierno: Actas IV Jornadas de Historia Social de la Patagonia. Santa Rosa, Universidad Nacional de La Pampa, 2011. Disponible en Internet: https:// sociohistoricos.files.wordpress.com/2011/11/ ponencia-abel.pdf

ABEL, J.L. La UCRI de Río Negro y la Convención Constituyente de 1957. En: Actas $4^{\circ}$ Jornadas de Historia de la Patagonia. Santa Rosa, Universidad Nacional de La Pampa, 2010. Disponible en Internet:

http://www.hechohistorico.com.ar/guardamemorias/trabajos/INSTITUCIONES, $\% 20$ BARRIOS, \%20GOBIERNO/JORNADAS\%20 HISTORIA $\% 2$ OPATAGONIA/2010/INSTITUCIONES/Abel\%20\%E2\% 80\% 9CLa \%20 UCRI\%20de \%20R\%C3\%ADo\%20Negro\%20 y\%20la\%20Convenci\%C3\%B3n\%20Constituyente\%20de\%201957\%E2\%80\%9D.pdf

ARGENTINA. Digesto Jurídico Provincial. Provincia de Río Negro. Boletín Oficial Provincial. Disponible en Internet: http://www. legisrn.gov.ar/DIGESCON/basica.php

ARIAS BUCCIARELLI, M. y FAVARO, O. Neuquén (Argentina) ¿economía de enclave y estado de bienestar? Realidad Económica, 2008, N²38, p. 95-119.

ARIAS BUCCIARELLI, M. Identidades en disputa: las "regiones" del Comahue y los poderes provinciales. Cuadernos del Sur, 2007, $N^{\circ} 35 / 36$, p. $151 / 174$.

ARIAS BUCCIARELLI, M. Tensiones en los debates parlamentarios en torno a la provincialización de los Territorios Nacionales durante el primer peronismo. Quinto Sol, 2010, $\mathrm{N}^{\circ} 14$, p.103-124.
BAJRAJ, R. Objetivos y estructura del seminario. En: CEPAL. La CEPAL en sus 50 años. Notas de un seminario Conmemorativo. Santiago de Chile: ONU, 2000, p. 13-17.

BANDIERI, S. Nuevas investigaciones, otra historia: La Patagonia en perspectiva regional. En: FERNÁNDEZ, S. (compilador.) Más allá del territorio. La historia regional y local como problema. Discusiones, Balances y Proyectos. Rosario: ProHistoria Ediciones, 2006, p.47-72

BENEDETTI, A. Los usos de la categoría región en el pensamiento geográfico argentino. Scripta Nova, 2009, Vol. XIII, No 286. Disponible en Internet: http://www.ub.edu/ geocrit/sn/sn-286.htm

BENDINI, M. y TSAKOUMAGKOS, P. LOS ámbitos de la pluriactividad. Agro, poblados, ciudades. Neuquén: EDUCo, 2012.

BIELSCHOWSKY, R. Sesenta años de la CEPAL: textos seleccionados del decenio 1998-2008. Buenos Aires: Siglo Veintiuno Editores, 2010.

CONSTITUCIÓN PROVINCIAL DE RIO NEGRO. Viedma, 10 de diciembre de 1957. Boletín Oficial, 1 de diciembre de 1959. Disponible en Internet: http://www.iestudiospenales.com.ar

CRUZ DEL SUR Panorama Provincia de Río Negro. Viedma: Gobierno de la Provincia de Río Negro, 1965.

ESPINOSA, C. En recuerdo del gobernador Edgardo Castello, a 50 años de su muerte. APP -Agencia periodística patagonia. 2014. Disponible en Internet: www.appnoticias.com.ar/desarro_noti.php?.cod=13051

FANJUL, J.D. Breves Lineamientos para una política turística. Bariloche: Municipalidad de San Carlos de Bariloche, 1964.

FANTINI, A. Provincia de Río Negro. Tres Años de Gobierno. Viedma: Secretaría de Relaciones Públicas, Poder Ejecutivo Provincia de Río Negro, 1961. 
FAVARO, O. y BUCCIARELLI, M. El lento y contradictorio proceso de inclusión de los habitantes de los Territorios Nacionales a la ciudadanía política: un clivaje en los años '30. Entrepasados, 1995, № 9, p. 27-42.

FAVARO, O.; ZAPATA, Y. y ARAYA, L. "Tierras de todos o de nadie". Las puebladas del Alto Valle de Río Negro en el contexto de las protestas de años 1960 - 1970. Actas 4tas Jornadas de Historia de la Patagonia. Santa Rosa, Universidad Nacional del La Pampa, 2010. Disponible en Internet: http://investigadores.uncoma.edu.ar/cehepyc/Favaro-Zapata-Araya.pdf

FEDELLI, L. Cipolletti, una comunidad en acción ¿conflicto social o pueblada? Neuquén: Educo, 2011.

FERNÁNDEZ, V.; VIGL, J. y SEVAL, M. Explorando la región. Territorios, escalas y relacionalidades. Revista de Geografía Norte Grande, 2012, No 51, p. 21-41.

FERRER, A. Ahorro interno y capital extranjero: la estrategia desarrollista del gobierno de Arturo Frondizi y una conversación con Rogelio Frigerio. Buenos Aires: Documentos individuales miembros del Grupo FENIX. Universidad de Buenos Aires, 2008. Disponible en Internet: http://www.econ.uba.ar/ planfenix/aportes/8/

FRIGERIO, R. Las condiciones de la victoria. Montevideo: Editorial A. Monteverde y Cía. Montevideo, 1963.

FRIGERIO, R. Estatuto del subdesarrollo. Buenos Aires: Editorial Buenos Aires, 1967.

GANIZA, M.D. Análisis crítico del discurso desarrollista de Rogelio Frigerio (Argentina 1958-1962) a través de la teoría de Marcelo Diamand. Mar del Plata: Tesis Licenciatura en Economía, Facultad de Ciencias Económicas y sociales. Universidad Nacional de Mar del Plata, 2013.

GARCÍA ÁLVAREZ, J. El estudio geohistórico de las divisiones territoriales subestatales en Europa y América Latina. Actualidad y renovación. Investigaciones Geográficas, 2003, № 31, p. 67-86.
GarCía BOSSIO, H. Pensamiento y praxis de Rogelio Frigerio, fundador del proyecto desarrollista en Argentina. Buenos Aires: Tesis de Doctorado en Ciencias Políticas, Instituto de Ciencias Políticas y Relaciones Internacionales, Facultad de Ciencias Sociales, Políticas y de la Comunicación, Universidad Católica Argentina, 2012. Disponible en: Internet: http://bibliotecadigital.uca.edu.ar/repositorio/tesis/pensamientopraxis-rogelio-frigerio.pdf

HIERNAUX, D. II. Las ciudades y las regiones. En: RAMÍREZ-VELÁZQUEZ, B.R. y PRADILLA-COBOS, E. (compiladores). Teorías sobre la ciudad en América Latina. México: UAM-SITESA, 2013, p. 53-82.

HIRSCHMAN, A.O. The Strategy of ECOnomical Development. New Haven: Yale University Press, 1958.

IUORNO, G. y CRESPO, E. (coordinadores). Nuevos Espacios, Nuevos Problemas. Los Territorios Nacionales. Neuquén: UNPaUNCo, 2008.

JONG, G.M. de. Análisis regional, estructuras agrarias y estrategias de desarrollo regional en la fruticultura del Alto Valle de la Cuenca del Río Negro. Mar del Plata: Tesis doctoral, Facultad de Humanidades y Ciencias de la Educación, Universidad Nacional de La Plata, 2008. Disponible en Internet: http://www.memoria.fahce.unlp.edu.ar/tesis/ te.272/te.272.pdf

LeIVA LAVALLE, J. Pensamiento y práctica de la planificación en América Latina. Santiago de Chile: CEPAL, Inst. Lat. y del Caribe de Planificación Económica y Social, 2012.

LÓPEZ, S. Establecimiento de la Estación Experimental Regional Agropecuaria INTA Bariloche en la formación de la provincia de Río Negro (1958-1976). Comahue: Tesis de Licenciatura en Historia, Facultad de Humanidades, Universidad Nacional del Comahue, 2014.

MANZANAL, M. Lo aparente y lo real en la estrategia de desarrollo económico en la provincia de Río Negro: 1958-1964. Revista interamericana de planificación, 1980, Vol. XIV, No 53 , p. 97-140. 
ME-RN PRO-5. Programa de Desarrollo Económico de Río Negro 1960/1964. Viedma: Dirección General de Política Económica. Ministerio de Economía de Río Negro, 1960.

MONNET, J. Globalización y territorializaciones "areolar" y "reticular": los casos de Los Ángeles y la ciudad de México: Memorias del V Seminario Internacional de la Red Iberoamericana de Investigadores sobre Globalización y Territorio. Toluca: Universidad Autónoma del Estado de México, 1999.

NAVARRO FLORIA, P. La Patagonia como 'reserva prodigiosa de la Patria'. Los planes de desarrollo de la época peronista (1943-1955) y la continuidad del colonialismo interno hacia los territorios nacionales. Cuadernos del Sur, 2009, Nº38, p. 281-310.

NAVARRO FLORIA, P. Utopía Agraria y Realidad Latifundista. El debate sobre las tierras públicas en la Patagonia norte hasta principios del siglo XX. En: MALDONADO, J.C. (director). La propiedad de la tierra, pasado y presente. Estudios de Arqueología, historia y antropología sobre la propiedad de la tierra en Argentina. Córdoba: Alción Editora, 2006, p. 168-200.

NÚÑEZ, P. La incompleta re-construcción peronista de la frontera: Un análisis desde la región del Nahuel. Estudios Fronterizos, nueva época, 2015, Vol. 16, № 31, p. 91-116.

NÚÑEZ, P. y VEJSBJERG, L. El turismo, entre la actividad económica y el derecho social: el Parque Nacional Nahuel Huapi, 1934-1955. Estudios y Perspectivas en Turismo, 2010, Vol. 19, № 6, p. $930-945$.

NÚÑEZ, P. Municipio y provincias. Una indagación en torno a la dinámica relacional a partir de un estudio de caso. Territorios, 2007, No16-17, p. 207-224.

PE-RN. Plan Trienal de Gobierno 19741976. Viedma: Secretaría de Planeamiento, 1973.

PERÓN, Primer Plan Quinquenal. Gobierno del Presidente Perón 1947 - 1951. Buenos Aires: Editorial Primicia, 1947.
PISARELLO VIRASORO, R. Arturo Frondizi, su pensamiento. Buenos Aires: Gráfica Integral, 2000.

PISARELLO VIRASORO, R. Cómo y por qué fue derrocado Frondizi. Buenos Aires: Editorial Biblos, 1996.

PREBISCH, R. El desarrollo económico de la América Latina y algunos de sus principales problemas. En: CEPAL. Cincuenta años de pensamiento en la CEPAL. Santiago de Chile: FCECEPAL, [1949] 1998.

RAPOPORT, M.; MADRID, E.; MUSACCHIO, A. y VICENTE, R. Historia económica, política y social de la Argentina: 1880-2000. Buenos Aires: Macchi, 2000.

REY, H. (compilador). La cordillera rionegrina. Economía, Estado y Sociedad en la primera mitad del siglo XX. Viedma: Editorial 2010 Bicentenario, 2005.

REY, H. y VIDAL, L. Historia de Río Negro. Texto para el establecimiento de enseñanza de la provincia. General Roca: Gobierno de Río Negro, 1975.

RÍO NEGRO. Diario. Fuerzas vivas de Bariloche reclaman. 16 de febrero de 1967, p. 5. Archivo General Diario Río Negro, General Roca.

RÍO NEGRO, d. Idevi, 40 años peleando por transformación económica. 2001. Disponible en Internet: http://www1.rionegro.com.ar/ arch200108/r06j02.html pp1-2

RODRIGUEZ MEITÍN, B. El Paralelo $42^{\circ}$ y la Frontera entre las áreas norte y sud del Espacio Económico argentino. Económica, 1960, Vol. VI, No 21-24, p. 131-163.

RODRÍGUEZ, O. Nuestras Estaciones Experimentales: Bariloche: Revista Integración, Investigación y Extensión Rural, 1982, Año 7, No 27, p. 4-36.

RUFFINI, M. Peronismo, Territorios Nacionales y ciudadanía política. Algunas reflexiones en torno a la provincialización. Revista Avances del Cesor, 2005, № 5, p. 132-148.

RUFFINI, M. Memorias de exclusión. Las argumentaciones justificadoras de la proscrip- 
ción peronista en Río Negro (1955-1966). En: Actas Congreso Pre-Alas. El Calafate, Universidad Nacional de La Patagonia, 2014. Disponible en Internet: http://prealas2014. unpa.edu.ar/sites/prealas2014.unpa.edu. ar/files/ckeditor/46/Memorias\%20de\%20 exclusi\%C3\%B3n\%20Las\%20argumentaciones $\% 20$ justificadoras $\% 20$....pdf

TAPIA, M.A. El Cipoletazo, una pueblada en el Alto valle de Río Negro. Recortes políticos en los tiempos de la revolución argentina. En: CAMINO VELA, F. (compilador). El mundo de la política en la Patagonia Norte. Neuquén: Educo, 2012, p. $111-146$.
VAPÑARSKY, C. Pueblos del Norte de La Patagonia 1779-1957. General Roca: De la Patagonia, 1983.

YAPPERT, S. y BOHOSLAVSKY, E. Liderazgo local, consignas nacionales y estrategias universales: el Rocazo 1972. En: CAMINO VELA, F. (compilador). El mundo de la política en la Patagonia Norte. Neuquén: Educo, 2012, p.147-172.

ZUSMAN, P. La geografía Histórica, la imaginación y los imaginarios geográficos. Revista de Geografía Norte Grande, 2013, Nº 54, p. 51-66. 